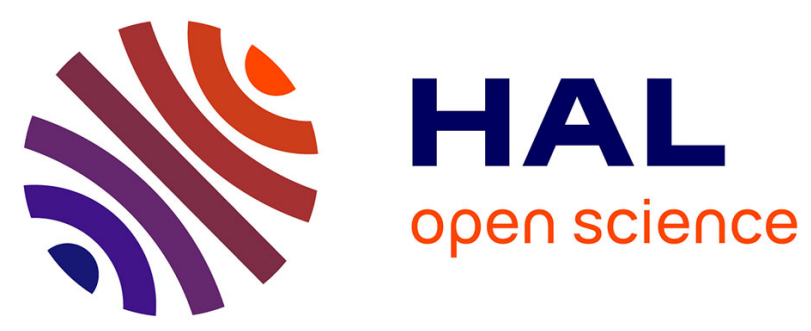

\title{
A previously undescribed organic residue sheds light on heat treatment in the Middle Stone Age
}

Patrick Schmidt, Guillaume Porraz, Ludovic Bellot-Gurlet, Edmund February, Bertrand Ligouis, Céline Paris, Pierre-Jean Texier, John E. Parkington, Christopher E. Miller, Klaus G. Nickel, et al.

\section{To cite this version:}

Patrick Schmidt, Guillaume Porraz, Ludovic Bellot-Gurlet, Edmund February, Bertrand Ligouis, et al.. A previously undescribed organic residue sheds light on heat treatment in the Middle Stone Age. Journal of Human Evolution, 2015, 85, pp.22-34. 10.1016/j.jhevol.2015.05.001 . hal-01345904

\author{
HAL Id: hal-01345904 \\ https://hal.science/hal-01345904
}

Submitted on 12 Jul 2018

HAL is a multi-disciplinary open access archive for the deposit and dissemination of scientific research documents, whether they are published or not. The documents may come from teaching and research institutions in France or abroad, or from public or private research centers.
L'archive ouverte pluridisciplinaire HAL, est destinée au dépôt et à la diffusion de documents scientifiques de niveau recherche, publiés ou non, émanant des établissements d'enseignement et de recherche français ou étrangers, des laboratoires publics ou privés. 


\title{
A previously undescribed organic residue sheds light on heat treatment in the Middle Stone Age
}

\author{
Patrick Schmidt ${ }^{\mathrm{a},}{ }^{*}$, Guillaume Porraz ${ }^{\mathrm{b}, \mathrm{c}}$, Ludovic Bellot-Gurlet ${ }^{\mathrm{d}}$, Edmund February ${ }^{\mathrm{e}}$, \\ Bertrand Ligouis ${ }^{f}$, Céline Paris ${ }^{\mathrm{d}}$, Pierre-Jean Texier ${ }^{\mathrm{g}}$, John E. Parkington ${ }^{\mathrm{h}}$, \\ Christopher E. Miller ${ }^{f}$, Klaus G. Nickel ${ }^{\mathrm{i}}$, Nicholas J. Conard ${ }^{\mathrm{a}}$ \\ a Eberhard Karls University of Tübingen, Department of Prehistory and Quaternary Ecology, Schloss Hohentübingen, 72070 Tübingen, Germany \\ ${ }^{\mathrm{b}}$ CNRS, USR 3336, UMIFRE 25, Institut Français d'Afrique du Sud (IFAS), Johannesburg, South Africa \\ ${ }^{c}$ Evolutionary Studies Institute, University of the Witwatersrand, Johannesburg, South Africa \\ 'Sorbonne Universités, UPMC Université Paris 6, MONARIS “de la Molécule aux Nano-objets: Réactivité, Interactions et Spectroscopies", UMR 8233, \\ UPMC-CNRS, 4 place Jussieu, 75252 Paris Cedex 5, France \\ e University of Cape Town, Department of Biological Sciences, Rondebosch 7701, South Africa \\ ${ }^{\mathrm{f}}$ Eberhard Karls University of Tübingen, Institute for Archaeological Sciences, Rümelinstrasse 23, 72070 Tübingen, Germany \\ ${ }^{g}$ CNRS, UMR 5199-PACEA, Université de Bordeaux 1, Talence, France \\ h University of Cape Town, Department of Archaeology, Rondebosch 7701, South Africa \\ ${ }^{\mathrm{i}}$ EberhardKarls University of Tübingen, Department of Geosciences, Applied Mineralogy, Wilhelmstraße 56, 72074 Tübingen, Germany
}

\section{A R T I C L E I N F O}

\section{Article history:}

Received 17 April 2014

Accepted 1 May 2015

Available online 12 June 2015

\section{Keywords:}

Modern behaviour

Silcrete heat treatment

Residue analysis

Transformative technology

\begin{abstract}
A B S T R A C T
South Africa has in recent years gained increasing importance for our understanding of the evolution of 'modern human behaviour' during the Middle Stone Age (MSA). A key element in the suite of behaviours linked with modern humans is heat treatment of materials such as ochre for ritual purposes and stone prior to tool production. Until now, there has been no direct archaeological evidence for the exact procedure used in the heat treatment of silcrete. Through the analysis of heat-treated artefacts from the Howiesons Poort of Diepkloof Rock Shelter, we identified a hitherto unknown type of organic residue - a tempering-residue - that sheds light on the processes used for heat treatment in the MSA. This black film on the silcrete surface is an organic tar that contains microscopic fragments of charcoal and formed as a residue during the direct contact of the artefacts with hot embers of green wood. Our results suggest that heat treatment of silcrete was conducted directly using an open fire, similar to those likely used for cooking. These findings add to the discussion about the complexity of MSA behaviour and appear to contradict previous studies that had suggested that heat treatment of silcrete was a complex (i.e., requiring a large number of steps for its realization) and resource-consuming procedure.
\end{abstract}

(C) 2015 Elsevier Ltd. All rights reserved.

\section{Introduction}

In recent years, human origins research has focused on South Africa as a key region for the beginnings of 'modern human behaviour' during the Middle Stone Age (MSA). The suite of behaviours that archaeologists view as characterizing the emergence of modernity includes the production of standardized stone tool types (Clark, 1988; McBrearty and Brooks, 2000) and elaborate bone tools (Henshilwood et al., 2001; Backwell et al., 2008), the invention of compound adhesives (Wadley, 2010; Charrié-Duhaut et al., 2013),

\footnotetext{
* Corresponding author.

E-mail address: patrick.schmidt@uni-tuebingen.de (P. Schmidt).
}

symbolic behaviour (Henshilwood et al., 2002, 2009; Texier et al. 2013) and heat treatment of silcrete, a local, fine-grained lithic raw material (Brown et al., 2009; Mourre et al., 2010). Because knapping heat-treated rock requires less force and allows better accuracy in obtaining the desired end-products (Crabtree and Butler, 1964; Purdy and Brooks, 1971; Inizan et al., 1976; Domanski et al., 1994; Schmidt et al., 2012) this knowledge may have been decisive in the evolutionary history of anatomically modern humans. Understanding the procedures used for lithic heat treatment, and the degree of complexity and investment associated with them, is thus of great importance. Some authors (Brown et al., 2009; Brown and Marean, 2010; Wadley, 2013; Wadley and Prinsloo, 2014) suggest a rather complicated procedure for heat treatment that is both time and resource consuming because it relies on slow, indirect heating in 
a sand-bath under a fire specially built for this purpose. Others (Schmidt et al., 2013) have argued that heat treatment of silcrete might have been a much faster and more efficient process using the glowing embers from regular domestic fires.

When silcrete is heated, it undergoes several readily identifiable physical changes. These changes include reddening (Schindler et al., 1982), occasional heat fracturing (Mercieca, 2000), the loss of porosity (Schmidt et al., 2013) and increased brittleness (Domanski and Webb, 1992). However, the identification of these characteristics does not directly imply intentional heating since, in post-depositional contexts, unintentional heating of artefacts can occur through indirect heating below a hearth or due to natural fires. Heat treatment may unambiguously be considered intentional only when one can demonstrate that an artefact was knapped after heating. This must be confirmed on the basis of technological arguments such as fracture pattern and sequence of flake negatives: fracture surfaces resulting from flakes removed after heat treatment (post-heating surfaces) are smoother or more glossy than fracture surfaces from before heat treatment (preheating surfaces) (Olausson and Larsson, 1982; Schmidt, 2013). This difference of fracture pattern is due to heat-induced transformations of the rocks' mechanical properties (Schmidt et al., 2012, 2013; Schmidt, 2013) and a comparison of the roughness allows one to determine whether a flake was knapped before or after heat treatment.

The scope of this work is to identify these markers of intentional heat treatment on silcrete artefacts from the Howiesons Poort of the South African MSA site of Diepkloof Rock Shelter (Western Cape, South Africa) and to compare them with experimental reference material. We also try to identify proxies that help us understand the procedures used for heat treatment in the MSA. In order to do so, we conducted heat treatment experiments using silcrete types recorded in the site and the wood of plant species growing in the vicinity of the shelter and documented in its MSA record (Cartwright, 2013). After a first study (Schmidt et al., 2013) that addressed the thermally induced structural and crystallographic transformations in South African silcrete, in order to understand the parameters necessary for heat treatment of this material, we aim in the present study to test the hypotheses about heat treatment procedures that resulted from our initial mineralogical study.

\section{Materials and methods}

\subsection{Archaeological samples}

We analysed all plotted silcrete artefacts from two Howiesons Poort (HP) stratigraphic units (SU) Frank and Frans. These two SUs were chosen because of their high proportion of silcrete artefacts (ca. 40\% of all lithic material [Porraz et al., 2013]). They both belong to what has been called the 'intermediate HP', characterized technologically by the production of blades and bladelets and typologically by the production of backed tools and strangulatednotched pieces. All of the plotted silcrete artefacts coming from an excavated surface of $6 \mathrm{~m}^{2}$ (squares N-M6, N-M7, N-M8 [Parkington et al., 2013]) were analysed and represent a total of 574 pieces for the SU Frank and 691 pieces for the SU Frans. Additionally, one unplotted silcrete artefact recovered from a profile collapse of the SUs John to Darryl (Intermediate and Late HP) was selected for destructive analyses.

\subsection{Experimental heat treatment}

For heat treatment experiments, we collected silcrete samples of good knapping quality from the Malmesbury area. Silcrete from this region is one of the materials that the MSA inhabitants of Diepkloof used extensively (Porraz et al., 2013). We built a set of outdoor camp fires using wood of four local southern African plant species that were reported in the charcoal record of the Diepkloof Howiesons Poort layers (Cartwright, 2013): Heeria argentea (Thunb.) Meissner, Diospyros glabra (L.), Searsia laevigata (L.) F.A. Barkley var. villosa (L.f.) Moffett and Podocarpus elongatus (Ait.) L' Herit. ex Pers. Three days before the heat treatment experiments, the wood of these four species was cut from living plants in the vicinity of the shelter. All fires used during the experiments were started in the same way: first, approximately $1-2 \mathrm{~kg}$ of the thinnest branches including green leaves was lit. When the leaves were burnt down and the thin branches became fine glowing embers, the thick white smoke caused by the leave's moisture disappeared and the first visible flames appeared. The thicker branches were then progressively added, building up a stable camp fire that could be sustained for several hours by adding more wood. This procedure allowed for the lighting of the freshly cut green wood without too much effort. Furthermore, this procedure allowed for the rapid formation of a cone of ash and embers at the base of the fire (up to $10 \mathrm{~cm}$ high at its centre) due to the burnt thin branches and leaves. The temperatures at different places within these camp fire structures (flames, glowing embers, ash cone at the base of the fires) were monitored using K-type thermocouples. Based on these fires, two experimental setups were used for heat treatment.

[Exp. 1]: As suggested by Schmidt et al. (2013), we scraped some glowing embers away from the bottom part of the camp fire and used these embers to cover a block of silcrete (at a distance of about $30 \mathrm{~cm}$ from the actual fire; Fig. 1a, b). The temperature evolution of three such silcrete/ember piles ( $P$. elongatus, $S$. laevigata and D. glabra) was monitored with K-type thermocouples placed under the blocks before the experiment (the probes were placed beneath the blocks at $>3 \mathrm{~cm}$ distance from the nearest glowing embers, measuring the effective heating rate in the silcrete). After four hours and $20 \mathrm{~min}$ the experiments were stopped and the silcrete was removed from the ashes that had cooled down.

[Exp. 2]: A second experiment was conducted in parallel using two of the fires (S. laevigata and D. glabra). For this, a block of silcrete was pushed directly into the ash-cone at the bottom of each fire (Fig. 1c, d). Measuring the temperature evolution within these blocks was not straightforward because the ash-cone already had an initial high temperature before the blocks were introduced. We therefore first placed a thermocouple at the bottom of the cone and then pushed the cold block of silcrete onto the probe. The blocks were left beneath the fires until these had stopped burning and cooled down but temperature recording beneath the blocks was stopped after two hours.

[Exp. 3]: We conducted a third set of experiments aiming to investigate the risk of overheating (Schmidt, 2014) of silcrete during the heat treatment procedure. This experiment did not aim to reproduce the actual conditions of heat treatment at Diepkloof but was designed to understand the relation between heat-induced fracturing (overheating) in different volumes of silcrete and high temperatures/fast heating-rates. For this, we tried to create 'extreme conditions' by applying temperatures and heating-rates to the silcrete that are higher than what can be expected using wood of the plant species identified from the charcoal at Diepkloof (Cartwright, 2013). Experiment 3 was therefore realized with the same procedure as Experiment 1 but using a southern African woody species, Acacia erioloba E.Mey, which is not endemic to Diepkloof but does produce particularly high temperatures and fast heating rates. When glowing, the embers of $A$. erioloba maintain a temperature above $500{ }^{\circ} \mathrm{C}$ for several hours without dying down, delivering a relatively high and constant amount of energy to the silcrete that is heated up to $550^{\circ} \mathrm{C}$ with a ramp rate of $20^{\circ} \mathrm{C} / \mathrm{min}$ (a 

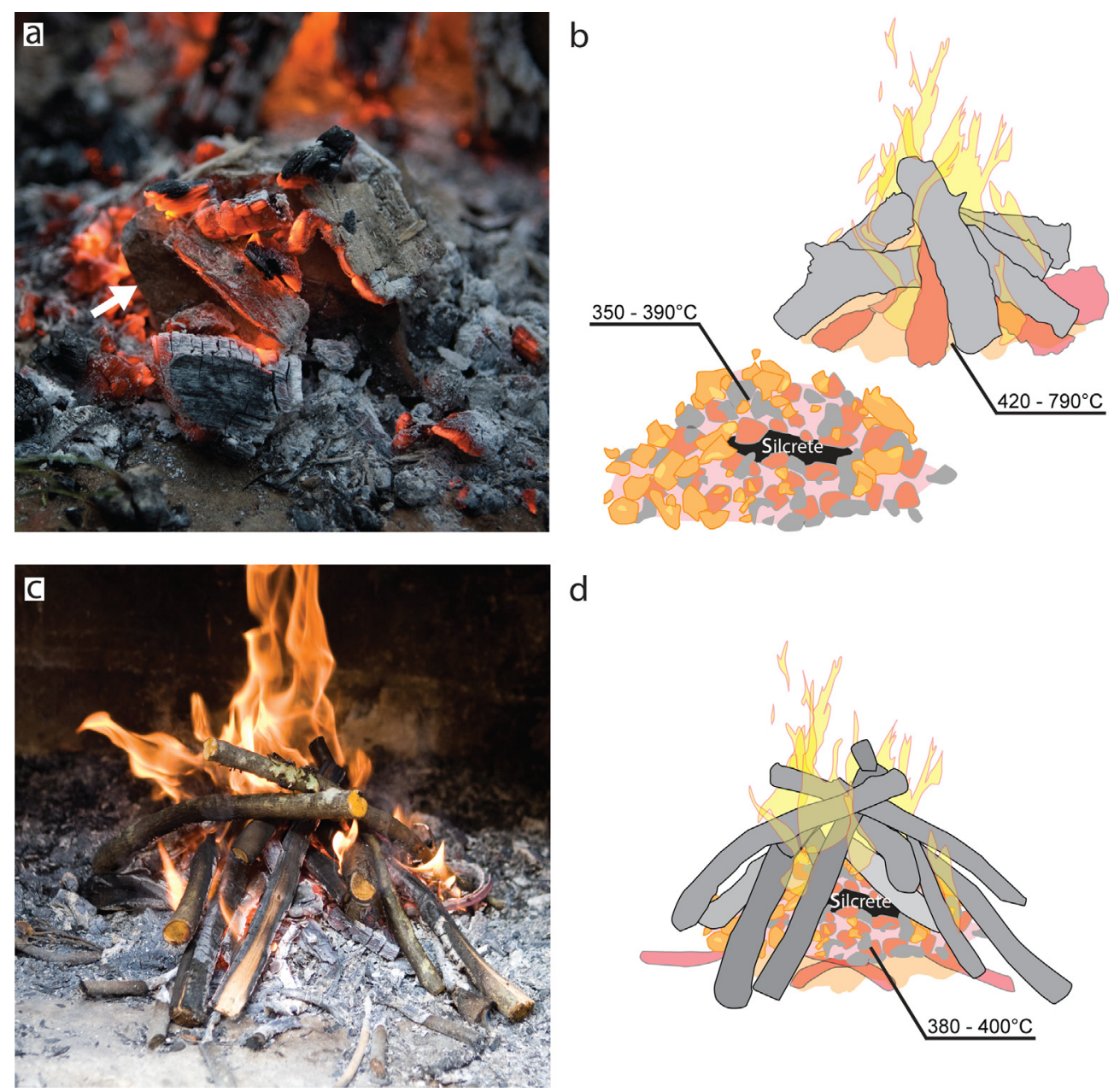

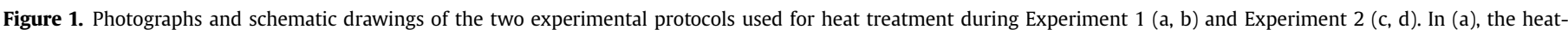

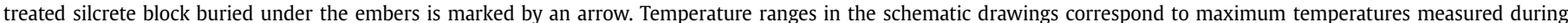
heat treatment experiments, cf. Figure 2.

typical temperature curve measured during Experiment 3 is shown in the Supplementary Online Material [SOM]). We conducted these heating experiments with 10 silcrete blocks of different volume (Table 1).

[Exp. 4]: To produce a larger reference collection of pre- and post-heating surfaces from a broader selection of silcrete types, we heat-treated 10 more blocks of different silcrete types from the West Coast of South Africa in an electrical furnace (average heating rate: $15^{\circ} \mathrm{C} / \mathrm{min}$; maximum temperature: $500{ }^{\circ} \mathrm{C}$; time at maximum temperature: two hours; then progressive cooling to room temperature). This larger reference collection helped in evaluating the smoothness of pre- and post-heating surfaces of the Diepkloof lithics by direct comparison. Sample provenances are summarized in Table 1 and petrographic and mineralogical descriptions of some of the samples can be found in Schmidt et al. (2013).

The effective cooling rate of the silcrete appears to be important for successful heat treatment. During preliminary experiments aimed at setting some of the parameters for Experiments 1,2 and 3, we observed a phenomenon that systematically leads to failure of the heat treatment. When we interrupted the heat treatment by removing the silcrete from the embers, a sequence of click sounds could be heard from within the pieces. Knapping of these pieces of silcrete after cooling to room temperature revealed them to be internally fractured and useless for stone tool production. This phenomenon was already observed by Micheelsen (1966) on flint and can most likely be explained by stress created in the rocks during negative thermal expansion upon fast cooling. Despite the lack of conclusive experimental data, we believe that in the case of silcrete, cooling rate is more crucial to the success or failure of heat treatment than heating rate. In order to eliminate fast cooling rates as a possible source of failure, the pieces of silcrete that were heat treated during all of our experiments were removed from their heating environments only after these had naturally cooled to room temperature.

\subsection{Chemical analysis of residues}

Examining the archaeological and experimentally heat-treated silcrete, we observed a black residue deposited on the surfaces of some of the archaeological and experimental samples. This residue was analysed microscopically to characterize its structure and formation. We therefore selected one bladelet (DRSc1) recovered from a profile collapse of the HP layers John to Darryl and, in order to compare the structure of the archaeological black residue with a modern reference sample, a flake was removed from one of the experimentally heat-treated blocks from Experiment 3. These two samples were cut with a diamond-tipped rock saw perpendicular to the surfaces containing the residues, embedded in resin and dry polished to obtain plane sections for reflected light microscopy. During dry polishing of the sections, we used low pressure, slow 
Table 1

Silcrete samples, origins, sample sizes and conditions used for heat treatment.

\begin{tabular}{|c|c|c|c|c|c|c|c|}
\hline Exp. nr & Sample nr & Nearest town to outcrop & Heating environment & Weight (g) & Volume $\left(\mathrm{cm}^{3}\right)$ & HINC & Tempering-residue \\
\hline \multicolumn{8}{|c|}{ Samples used during the experiments using fires: } \\
\hline [Exp. 1] & WK-13-08b & Malmesbury & S. laevigata embers & 182 & 69 & No & Yes \\
\hline [Exp. 2] & WK-13-08b & Malmesbury & S. laevigata ash cone & 397 & 151 & No & Yes \\
\hline [Exp. 1] & WK-13-08b & Malmesbury & D. glabra embers & 197 & 75 & No & Yes \\
\hline [Exp. 2] & WK-13-08b & Malmesbury & D. glabra ash cone & 188 & 71 & Yes & Yes \\
\hline [Exp. 1] & WK-13-08b & Malmesbury & P. elongates embers & 256 & 97 & No & Yes \\
\hline [Exp. 1] & WK-13-08b & Malmesbury & $H$. argentea embers & 169 & 64 & No & Yes \\
\hline [Exp. 3] & WK-13-08b & Malmesbury & A. erioloba embers & 205 & 78 & No & No \\
\hline [Exp. 3] & WK-13-08b & Malmesbury & A. erioloba embers & 301 & 114 & No & Yes \\
\hline [Exp. 3] & WK-13-08b & Malmesbury & A. erioloba embers & 445 & 169 & No & Yes \\
\hline [Exp. 3] & WK-13-08b & Malmesbury & A. erioloba embers & 569 & 216 & Yes & No \\
\hline [Exp. 3] & WK-13-08b & Malmesbury & A. erioloba embers & 905 & 344 & Yes & No \\
\hline [Exp. 3] & WK-13-08b & Malmesbury & A. erioloba embers & 1038 & 394 & Yes & Yes \\
\hline [Exp. 3] & WK-13-08b & Malmesbury & A. erioloba embers & 1372 & 521 & No & No \\
\hline [Exp. 3] & WK-13-08b & Malmesbury & A. erioloba embers & 1511 & 574 & No & Yes \\
\hline [Exp. 3] & WK-13-08b & Malmesbury & A. erioloba embers & 1715 & 651 & Yes & No \\
\hline [Exp. 3] & WK-13-08b & Malmesbury & A. erioloba embers & 1850 & 702 & No & Yes \\
\hline \multicolumn{8}{|c|}{ Samples used during the furnace experiment: } \\
\hline [Exp. 4] & SA-11-2 & Redelinghuys & furnace & 83 & 32 & No & No \\
\hline [Exp. 4] & SA-11-10A & Philadelphia & furnace & 26 & 10 & No & No \\
\hline [Exp. 4] & SA-11-12A & Malmesbury & furnace & 166 & 63 & No & No \\
\hline [Exp. 4] & SA-11-17A & Velddrif & furnace & 188 & 71 & No & No \\
\hline [Exp. 4] & SA-11-22A & Piketberg & furnace & 109 & 41 & No & No \\
\hline [Exp. 4] & SA-11-22B & Piketberg & furnace & 67 & 25 & Yes & No \\
\hline [Exp. 4] & SA-11-56 & Strandfontein & furnace & 56 & 21 & No & No \\
\hline [Exp. 4] & SA-11-56b & Strandfontein & furnace & 25 & 9 & No & No \\
\hline [Exp. 4] & SA-11-61F & Koekenaap & furnace & 33 & 13 & No & No \\
\hline [Exp. 4] & SA-11-65B & Brand se Baai & furnace & 102 & 39 & No & No \\
\hline
\end{tabular}

Volumes are calculated from the mass of the blocks based on the specific gravity of quartz $2.634 \mathrm{~g} / \mathrm{cm}^{3}$. HINC $=$ Heat-induced non-conchoidal fracture.

polishing-wheel speed and no water or oil for cooling to avoid any alteration or loss of organic matter through dissolution. The two sections were analysed under white and blue reflected light using a Leitz DMRX microscope with oil immersion lenses at magnifications from $200 \times$ up to $1000 \times$.

In the second step, we investigated the chemical composition of the archaeological residues by infrared spectroscopy using nondestructive micro-ATR analysis on the surfaces of six lithic artefacts from Diepkloof (DRSc1 and DRSc8 from the collapse of SUs John to Darryl; DRS894, DRS762, DRS2676 and DRS1276 from SU Frank). A Bruker IRscope II microscope with a $20 \times$ germanium-ATR objective connected to an FT-IR Equinox 55 spectrometer was used for this infrared ATR surface analysis (maximum size of the analysed area $100 \mu \mathrm{m}^{2}$, spectra acquired between 600 and $4000 \mathrm{~cm}^{-1}$, resolution $2 \mathrm{~cm}^{-1}$ ). In order to compare the chemistry of the archaeological residue to a possible modern source material, we burned a drop of resin from $H$. argentea wood collected during fieldwork and analyzed it using diamond ATR-IR (Agilent Cary 660IR FTIR spectrometer, spectra acquired between 600 and $4000 \mathrm{~cm}^{-1}$, resolution $1 \mathrm{~cm}^{-1}$ ).

Additionally, we acquired Raman spectra between 100 and $1900 \mathrm{~cm}^{-1}$ on the seven samples with a Horiba Jobin Yvon HR800 spectrometer equipped with Notch Brag Grate filters, an $\mathrm{Ar}^{+}$ exciting laser (wavelength $514 \mathrm{~nm}$ ) and a 600 lines/mm grating. The spectrometer was calibrated using the $520.5 \mathrm{~cm}^{-1}$ band of a $\mathrm{Si}$ crystal.

\section{Results}

\subsection{Experimental heat treatment}

The temperatures measured at different places in the four fires using green wood are summarized in Table 2. These fires using four different woody species $(H$. argentea, $D$. glabra, S. laevigata, $P$. elongatus) exhibited rather different temperatures with none of the ash cones at the bottom of these fires showing temperatures above $500{ }^{\circ} \mathrm{C}$.

Temperature evolution curves of the embers/silcrete piles of Experiment 1 and of the silcrete in the ash-cones of Experiment 2 are shown in Figure 2. Heat treatment of silcrete during Experiment 1 produced maximum temperatures of $\approx 350^{\circ} \mathrm{C}$ using $P$. elongatus and S. laevigata and $\approx 390{ }^{\circ} \mathrm{C}$ using $D$. glabra (Fig. 2a). Effective heating rates within the silcrete blocks can be estimated to be between $4{ }^{\circ} \mathrm{C} / \mathrm{min}$ and $5{ }^{\circ} \mathrm{C} / \mathrm{min}$, being fastest in the beginning of the heating process with up to $8{ }^{\circ} \mathrm{C} / \mathrm{min}$. The two silcrete blocks of Experiment 2 were heated to maximum temperatures of $\approx 380-400{ }^{\circ} \mathrm{C}$ and underwent heating rates of $9{ }^{\circ} \mathrm{C} / \mathrm{min}$ (Fig. 2b). Five of the six blocks heated during Experiments 1 and 2 do not show any sign of overheating (cracking or crazing) whereas the silcrete heated in the D. glabra ash-cone had fractured (Table 1). Maximum temperatures and heating rates during Experiment 3 ( $\approx 550^{\circ} \mathrm{C}$ and $\approx 20^{\circ} \mathrm{C} / \mathrm{min}$ ) were significantly higher than the ones produced by the wood of the four plant species of Experiment 1 and 2 (SOM Fig. 1). After these 'extreme heating conditions', six of the 10 silcrete blocks heated in Experiment 3 do not show any sign of overheating and four blocks had fractured in their peripheral areas (Table 1). The inner, intact part of all fractured blocks, which shows no signs of overheating, could be knapped perfectly and the only effect of the heat-induced fractures is a reduction of the effective

Table 2

Temperatures (Temp.) measured at different places in the fires used for heat treatment

\begin{tabular}{lcll}
\hline Plant species & $\begin{array}{c}\text { Temp. of } \\
\text { flames }\end{array}$ & $\begin{array}{c}\text { Temp. of glowing } \\
\text { embers }\end{array}$ & $\begin{array}{c}\text { Temp. within the ash cone } \\
\text { at the bottom of the fire }\end{array}$ \\
\hline P. elongatus & $880{ }^{\circ} \mathrm{C}$ & $790{ }^{\circ} \mathrm{C}$ & $480{ }^{\circ} \mathrm{C}$ \\
H. argentea & $730{ }^{\circ} \mathrm{C}$ & $520{ }^{\circ} \mathrm{C}$ & $430{ }^{\circ} \mathrm{C}$ \\
D. glabra & $630{ }^{\circ} \mathrm{C}$ & $560{ }^{\circ} \mathrm{C}$ & $420{ }^{\circ} \mathrm{C}$ \\
S. laevigata & $750{ }^{\circ} \mathrm{C}$ & $580{ }^{\circ} \mathrm{C}$ & $460{ }^{\circ} \mathrm{C}$ \\
\hline
\end{tabular}



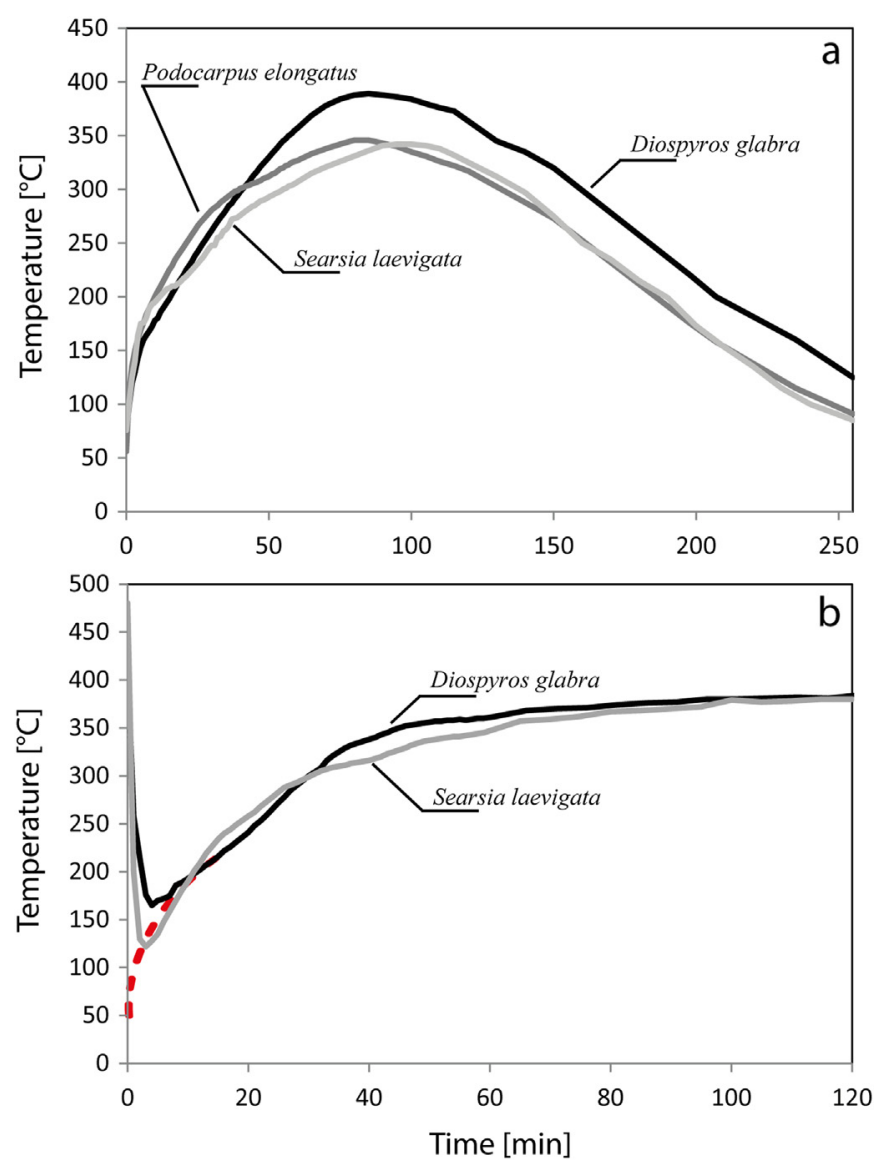

Figure 2. Temperature curves measured during Experiment 1 and Experiment 2. (a) $=$ [Exp. 1]: heat treatment in embers scraped away from a fire, (b) $=$ [Exp. 2]: heat treatment in the ash-cone at the bottom of a burning fire. For details about the temperature measurements and placements of the probes, see section Materials and methods.

knappable volume. Once the heat-treated silcrete blocks had cooled to ambient temperature, we removed them from the ashes and knapped a few flakes. All of these flakes have smoother fracture surfaces than control flakes removed before the procedure, thereby indicating successful heat treatment. Thus, even though heatinduced fracturing occurred in some of our samples, this did not compromise the overall aim of the heat treatment, i.e., increasing the quality of the raw material for knapping. Furthermore, no clear correlation between heat-induced fracturing and volume could be established during our experiments.

All six silcrete blocks heat-treated in Experiment 1 and 2 exhibit a thin black film coating part of their surface (Fig. 5e, f, Fig. 6d). This black opaque film, which appears to be a residue resulting from the contact between silcrete and embers/ashes, is insoluble in water or ethanol, tightly adheres to the surface and cannot be rubbed off by hand or with a brush. Five blocks heat-treated during Experiment 3 also exhibit this black film on part of their surface. Because this black residue can clearly be assigned to heat treatment of the silcrete, we hence call it a 'tempering-residue'.

During Experiment 4, the electrical furnace experiment, one of the 10 blocks cracked peripherally but the two resulting fragments show no signs of overheating. When knapped, all heat-treated silcrete exhibited post-heating fracture surfaces that are smoother than the pre-heating surfaces (compare Fig. 3a and b). The silcrete heat-treated in the furnace does not show any alteration of the surface and no film or residue can be observed on the surface.

\subsection{Flake scar roughness on artefacts and experimental samples}

Our results of the comparison between experimentally heattreated reference samples and archaeological artefacts from SUs Frans and Frank are shown in Table 3. From layer Frans, 96.7\% of all analyzed artefacts were knapped after heat treatment as indicated by the presence of smooth post-heating removal scars. From layer Frank, 93.7\% of all artefacts could clearly be identified as knapped after heat treatment. Nineteen percent of the artefacts from Frans and $23.2 \%$ of the artefacts from Frank preserve rough pre-heating removal scars in addition to the post-heating scars (Fig. $3 c-f$ ).

During our heat treatment experiments, we had also observed another type of fracture that is not due to conchoidal fracturing as it occurs during knapping. This type of fracture is induced by heating of the silcrete, hence we call it 'heat-induced non-conchoidal fracture' (HINC-fracture). Such fractures can be easily recognized visually: surfaces resulting from heat-induced failure (HINC-fracture-surfaces) show strong roughness and abundant scalar features that are rare on conchoidal fracture negatives (Fig. 4). From a lithictechnological point of view, it is of great importance to distinguish whether a heat-induced fracture occurred after discard of the artefact, i.e., during post-depositional burning, or before knapping, i.e., during heat treatment of the silcrete prior to knapping. In the latter case it may be concluded that heat-induced fracturing was an 'acceptable accident' after which knapping could still be performed. In order to make this distinction on Diepkloof artefacts, we identified as HINC-fractures only fracture-surfaces that are clearly cross-cut by a post-heating removal scar (according to the criteria in (Tixier et al., 1980)), indicating that knapping was done after the heating. We observed such HINC-fractures on $7.2 \%$ of the artefacts from Frans and $10.5 \%$ of the artefacts from Frank (Fig. 4d-f).

We also observed a black opaque film on 22 artefacts from Frans and 31 artefacts from Frank (Fig. 5a-d) that had resisted burial and washing. This film is visually similar to the black film identified on the samples from our heat treatment experiments. On some artefacts, this residue covers a natural surface of the silcrete (weathered or rolled exterior of the initial block used as raw material) whereas on other artefacts it covers a pre-heating surface, hence, formed after a first stage of knapping prior to heat treatment. None of the smooth post-heating surfaces are covered by a black film or residue. On the contrary, the film is always cross-cut by the adjacent, clean, postheating fracture negatives (Fig. $5 \mathrm{a}-\mathrm{d}$ ) indicating that its formation on the silcrete surface was followed by a sequence of knapping. The similarity of this archaeological residue with the black film produced during our heat treatment experiments, the tempering-residue, and the moment of its formation in the lithic chaîne opératoire (i.e., after a first stage of pre-heat-treatment-knapping but before knapping of the heat-treated silcrete) strengthens the hypothesis that the archaeological residue results from the heat treatment itself. To confirm whether the black films observed on artefacts and experimental samples are indeed the same and to investigate the origin and formation of the residue, we analysed them using optical microscopy, infrared and Raman spectroscopy.

\subsection{Structural and chemical analysis}

3.3.1. Microscopic analysis Under the reflected light microscope, the structure of experimental and archaeological black residues is very similar. They appear in both samples as a 1-to-20 $\mu$ m-thick deposit or film on the surface of the silcrete artefacts (Fig. 6a-c, e, f). Thicker parts show flow textures with pores formed by melt degassing (Fig. 6b, c, f), indicating that the deposit was a liquid during formation. Strongly reflecting micrometre-sized charcoal particles (inertodetrinite [Taylor et al., 1998]) are cemented within the residue. Thus, the archaeological and experimental 

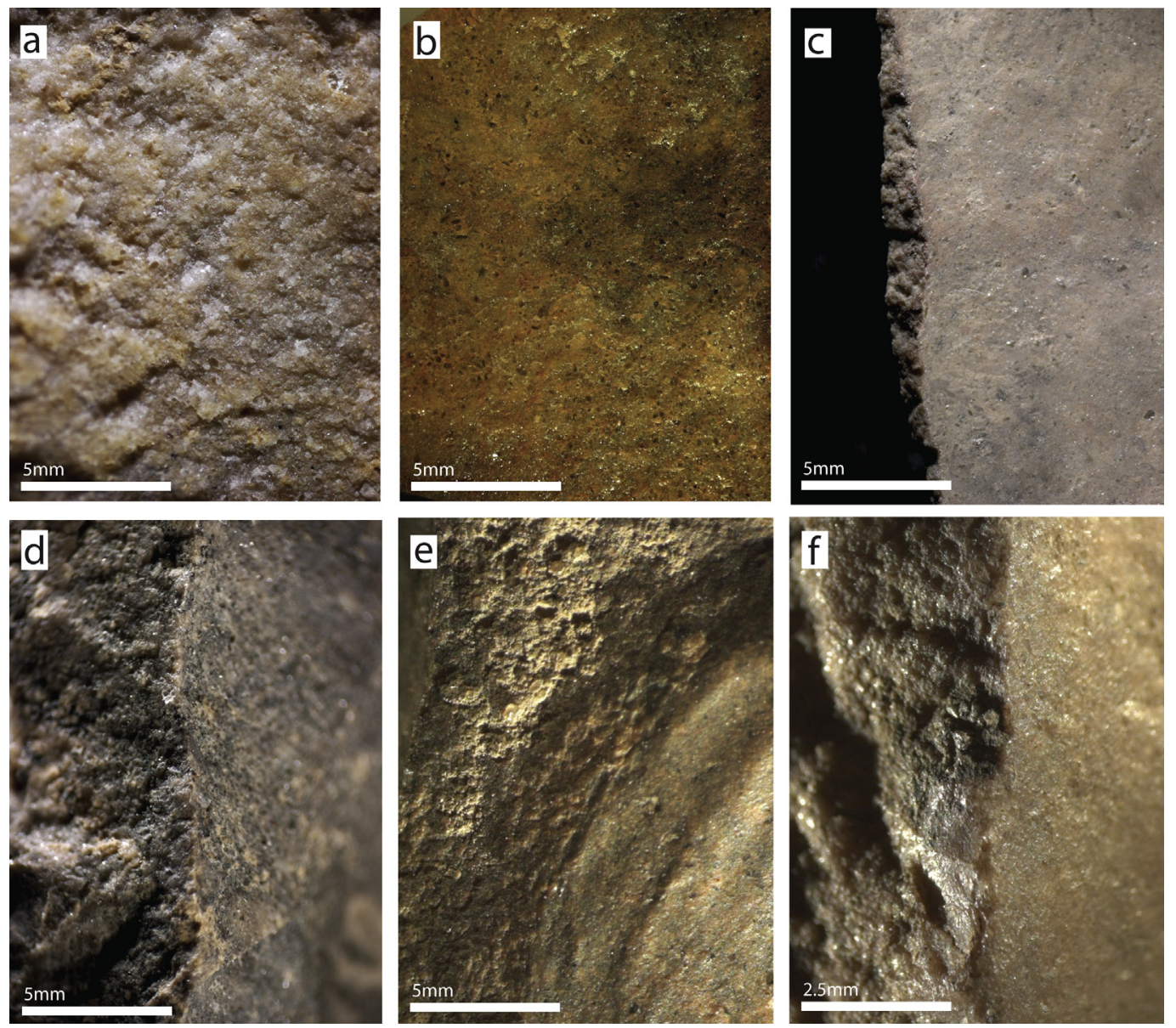

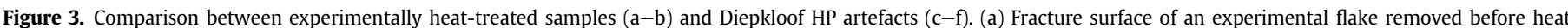

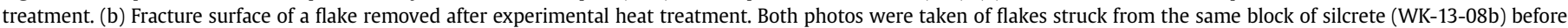

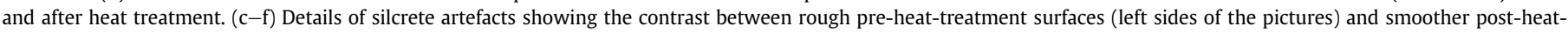
treatment surfaces on DRS816 (c), DRS1541 (d), DRS803 (e) and DRS928 (f).

residues were both deposited on the silcrete surface in a liquid state at high temperatures (melt degassing pores, flow texture) and formed in the direct vicinity of charcoal (micrometre-sized inertodetrinite fragments).

3.3.2. Infrared and Raman spectroscopy The infrared spectra of the six analysed archaeological samples show the expected quartz

Table 3

Results of the analysis of flake scar roughness of plotted artefacts from SUs Frank and Frans of Diepkloof Rock Shelter.

\begin{tabular}{lrc}
\hline SU Frans, total of analyzed artefacts: 691 & Count & Percent \\
\hline Artefacts with post-heating removal scars & 668 & $96.7 \%$ \\
Artefacts with pre- and post-heating removal scars & 131 & $19.0 \%$ \\
Non-diagnostic or not heat-treated artefacts & 23 & $3.3 \%$ \\
Artefacts with HINC-fracture surfaces & 50 & $7.2 \%$ \\
Total of artefacts with black tempering-residue & 22 & $3.2 \%$ \\
- of which the residue is found on pre-heating removal scars & 11 & $1.6 \%$ \\
- of which the residue is found on a natural surface & 11 & $1.6 \%$ \\
\hline SU Frank, total of analyzed artefacts: 574 & & \\
\hline Artefacts with post-heating removal scars & 538 & $93.7 \%$ \\
Artefacts with pre- and post-heating removal scars & 133 & $23.2 \%$ \\
Non-diagnostic or not heat-treated artefacts & 36 & $6.3 \%$ \\
Artefacts with HINC-fracture surfaces & 60 & $10.5 \%$ \\
Total of artefacts with black tempering residue & 31 & $5.4 \%$ \\
- of which the residue is found on pre-heating removal scars & 14 & $2.4 \%$ \\
- of which the residue is found on a natural surface & 17 & $3.0 \%$ \\
\hline
\end{tabular}

Percentages refer to the total of analyzed artefacts in each layer. bands resulting from the silcrete artefacts and additional $\mathrm{CH}$ bands at $2857 \mathrm{~cm}^{-1}$ and $2928 \mathrm{~cm}^{-1}$ with a shoulder near $2960 \mathrm{~cm}^{-1}$ confirming the presence of an organic compound. Some of the spectra also show a sharp $\mathrm{C}=\mathrm{O}$ band caused by carbonyl groups at $1740 \mathrm{~cm}^{-1}$ and two broad bands with several shoulders and features between $1380 \mathrm{~cm}^{-1}$ and $1650 \mathrm{~cm}^{-1}$ indicating a complex mixture of organic structures (bands related mainly to CO vibrations; Fig. 7b, c). Reference spectra acquired on post-heating surfaces of the artefacts show only quartz bands and no organic components (Fig. 7d). Thus, the archaeological residue is clearly an organic substance coating the silcrete.

The spectrum of the experimentally burned droplet of $H$. argentea resin shows $\mathrm{CH}$ bands at identical positions and with similar shape as observed in the spectra of archaeological residues. The carbonyl group band at $1740 \mathrm{~cm}^{-1}$ is also present as shoulder and several bands appear between $1380 \mathrm{~cm}^{-1}$ and $1650 \mathrm{~cm}^{-1}$ indicating a complex mixture of chemicals (Fig. 7a). The direct comparison of the burnt resin and the spectra of archaeological samples is not straightforward because some of the organic substances contained in the residue during its formation may have been transformed or lost during taphonomic processes. However, a great number of IR bands observed in the burnt $H$. argentea resin spectrum are observed at least as features in the spectra of the archaeological residues (Fig. 7a, b, c, left inset), suggesting that both residues may have similar chemical composition. 

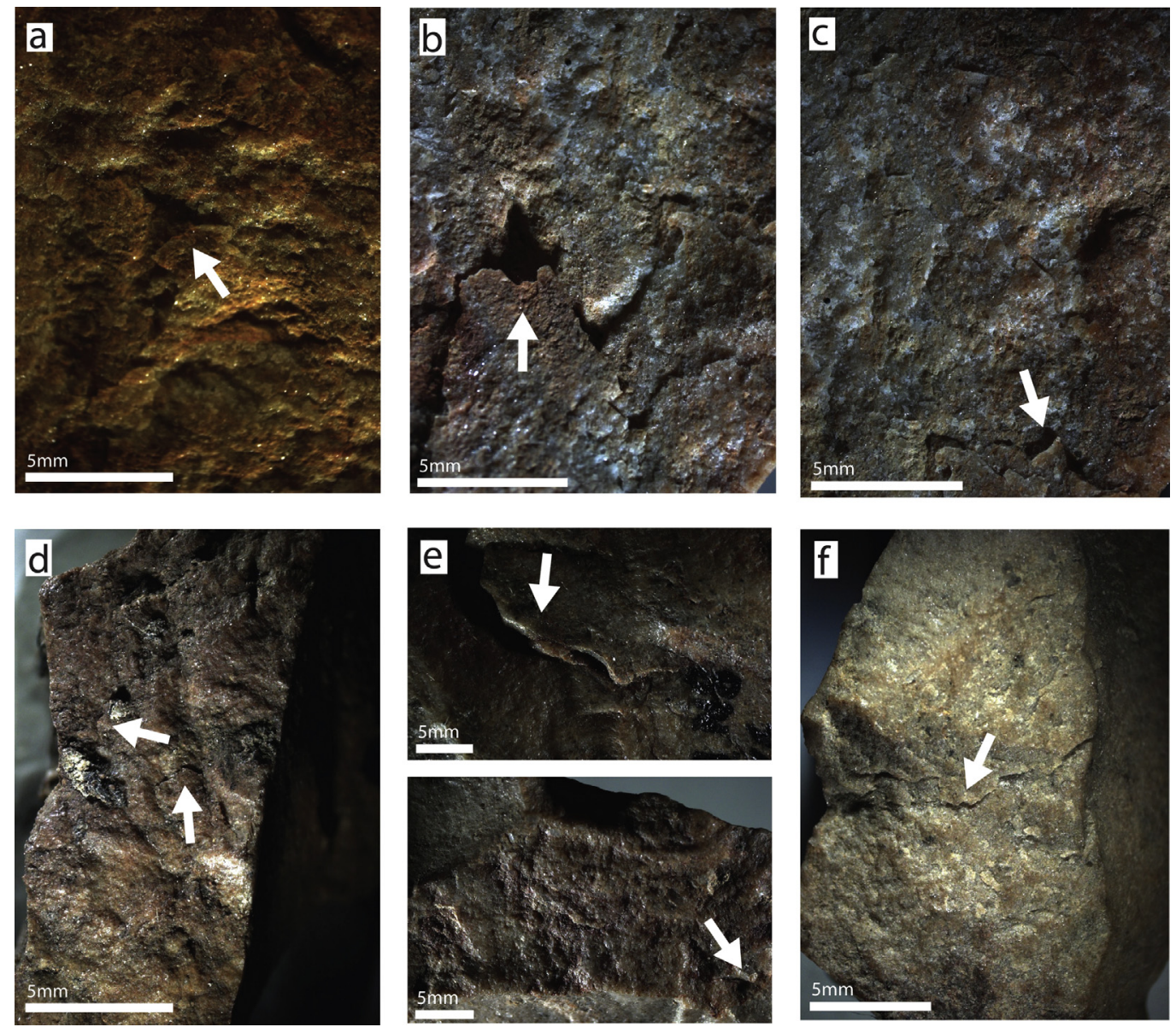

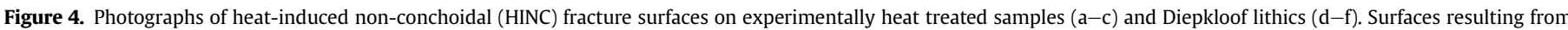

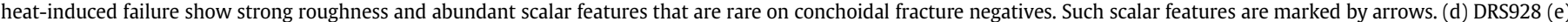
DRS2074 (f) DRS2200.

Our Raman spectroscopic measurements of both experimental and archaeological residues also show identical spectra with two CC bands at $1370 \mathrm{~cm}^{-1}$ (D band) and $1595 \mathrm{~cm}^{-1}$ (G band) (Fig. 7e, f). These CC bands, dominating the Raman spectra because of the resonance of the CC bonds with the $514 \mathrm{~nm}$ exciting laser, have identical shapes and positions in both samples. Our Raman spectra reveal chemical bonds, which are not infrared active and that are produced when organic substances are burnt at high temperature through pyrolysis (Tomasini et al., 2012).

\section{Discussion}

\subsection{Terminology used in this work}

We use the term 'smooth' in our work (as the opposite of 'rough') as equivalent to 'gloss' in previous publications (Brown et al., 2009). The reason we prefer the terms 'smooth' and 'rough' in our work to 'glossy' and 'dull' is because gloss was physically measured using a gloss-meter in previous works on South African South Coast silcrete (Brown et al., 2009) and we rather observed a distinction in micro-relieve on the analyzed West Coast silcrete types. The second term we use is 'HINC-fracture' that has a different meaning than 'pot-lid'. This distinction is made because the term HINC-fracture describes a fracturing event that occurs during heat treatment and after which knapping continued (i.e., HINC fractures are cross-cut by smooth post-heating-scars). Therefore, 'HINC' has a technological meaning. The term 'pot-lid' merely describes a concave feature due to heat induced fracturing without the notion of a continuing reduction sequence after the heat fracture occurred (i.e., pot-lids may also occur during burning after discard).

\subsection{The experimental heat treatment procedure}

Using wood from plants identified in high abundance in the Diepkloof deposits (Cartwright, 2013), both of our experiments (Experiments 1 and 2) successfully heat treated silcrete from the West Coast of South Africa. This finding corroborates the prediction made in our previous work (Schmidt et al., 2013), that heat treatment of silcrete could have been practiced in the South African MSA using the embers of domestic fires. The relatively low heat treatment temperatures of $380-400{ }^{\circ} \mathrm{C}$ in the ash-cones of Experiment 2 may appear contradictory to the measurements of the glowing embers' temperatures of $520-790^{\circ} \mathrm{C}$. This may be explained by the following mechanism: the glowing embers at the outside of the cone consume most of the oxygen, preventing the combustion of the inner part of the ash-cone that remains at a relatively lower temperature. This cooler inner part of the ash-cone insulates the silcrete from the hot glowing embers. The same is true for large piles of embers scraped away from a fire. Thus, larger ash-cones or piles of embers produce lower temperatures in their centre because combustion is slowed down due to the restricted access of oxygen; smaller piles produce higher temperatures because of the 
a
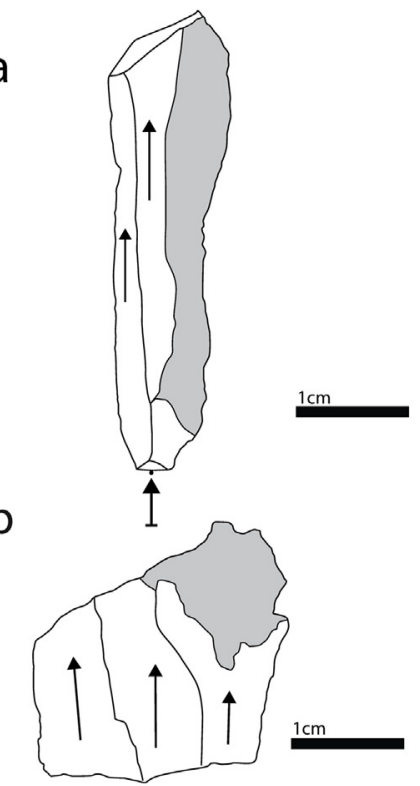

c

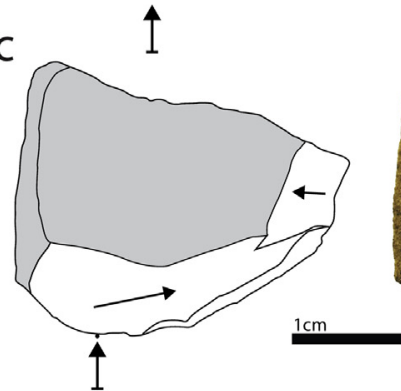

d

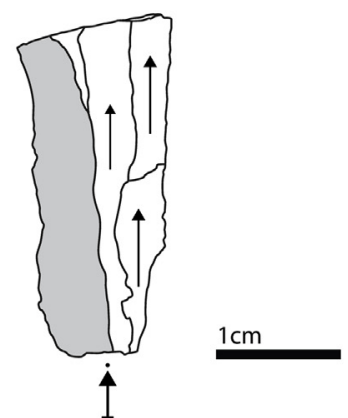

Diepkloof Lithics
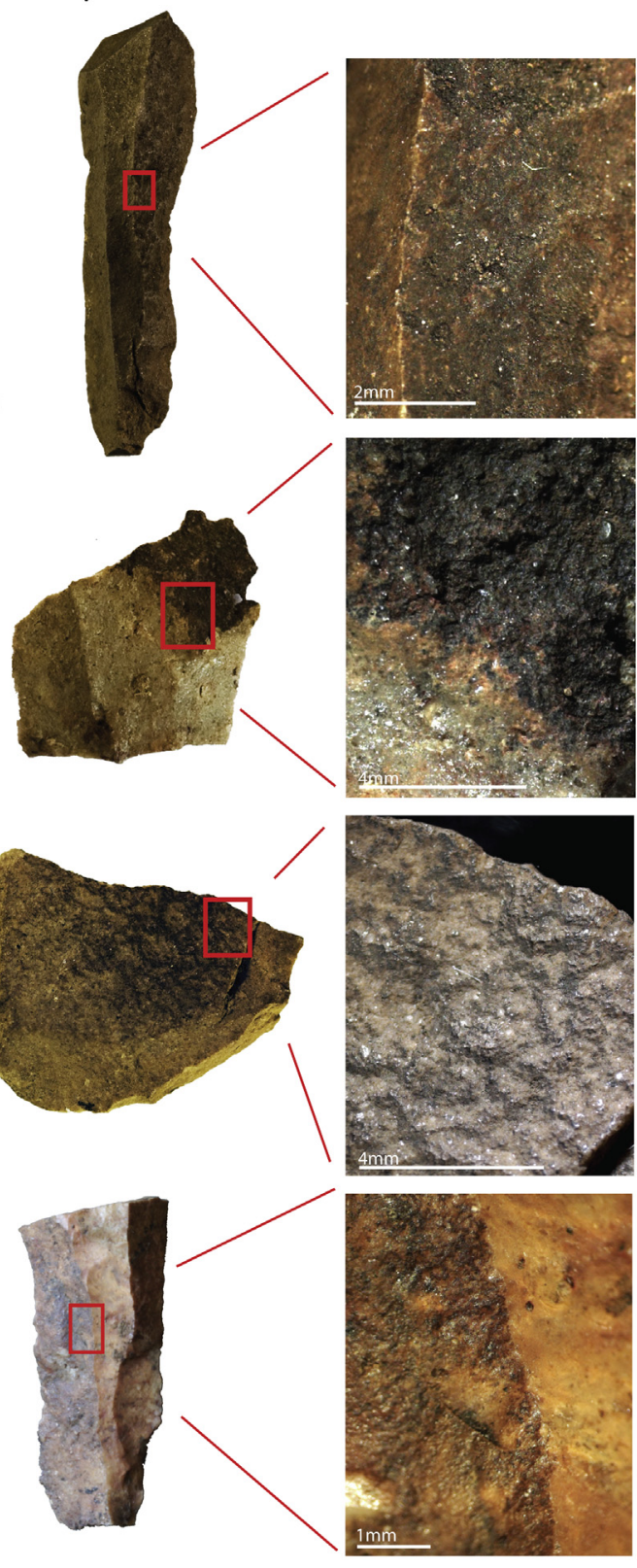

\section{Experimental tempering residue}
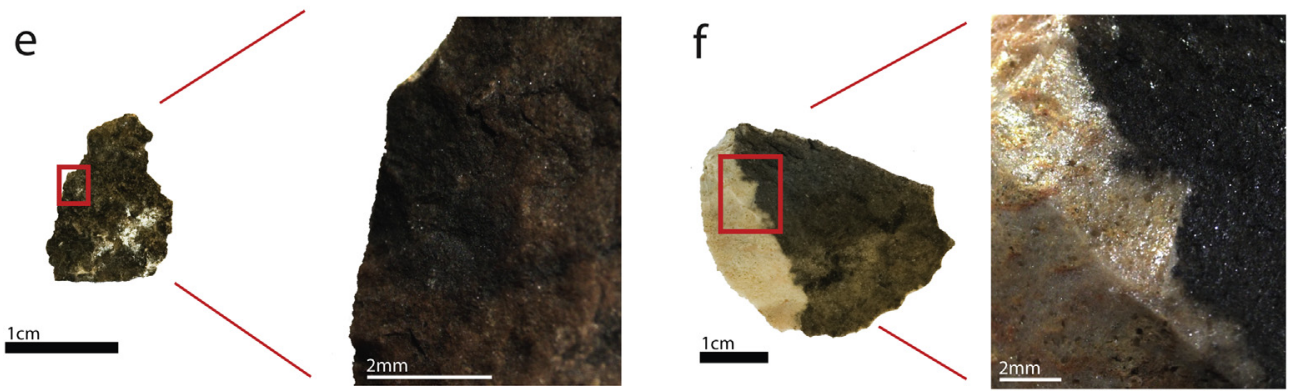

Figure 5. Photographs, technical drawings and Macro-photos of tempering-residue observed on Diepkloof artefacts (a-d) and experimentally heat treated silcrete (e-f). (a) DRSc1, (b) DRS894, (c) DRSc8, (d) DRS2676, (e, f) experimentally heat-treated fragments of sample WK-13-08b. Note the black tempering-residue (represented as grey surfaces in the technical drawings) that covers rough pre-heating surfaces. The residue is cut by smooth post-heating fracture negatives of flakes removed after heat treatment (a-d). 

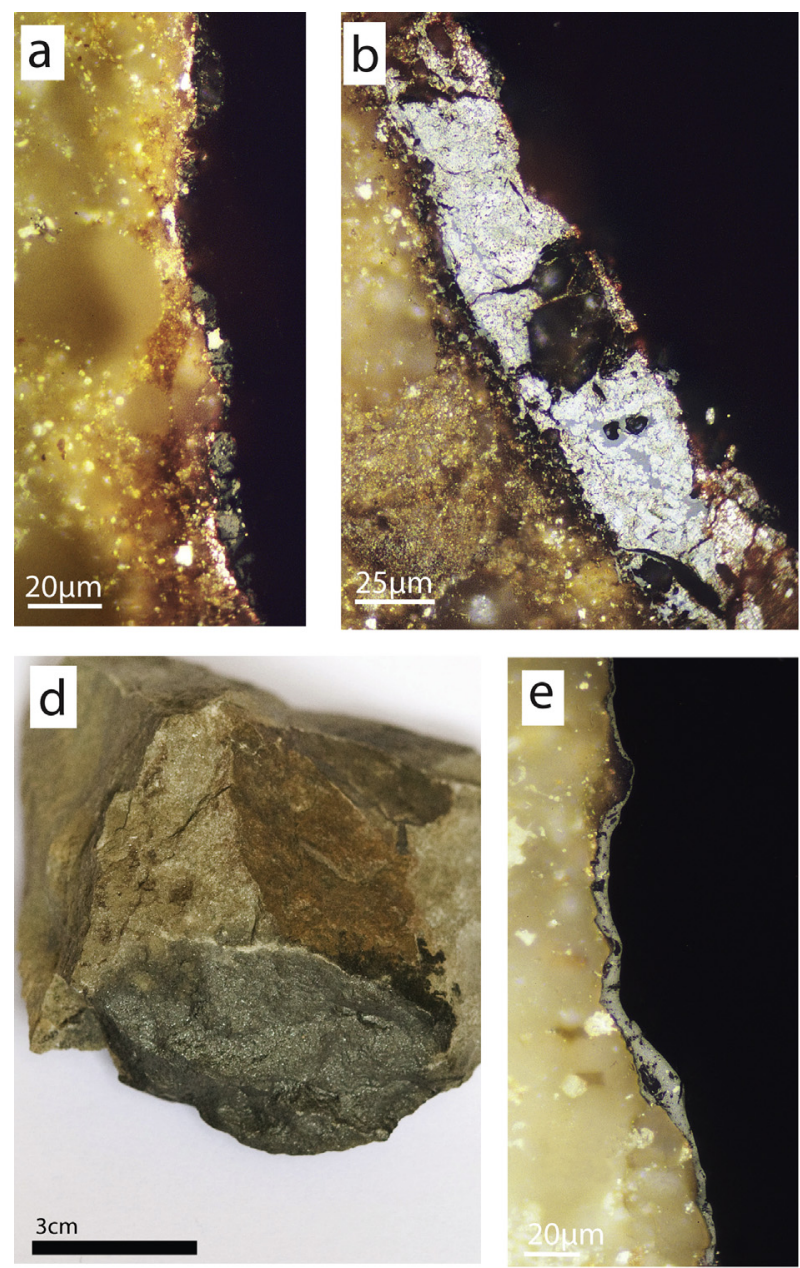

Degassing pores
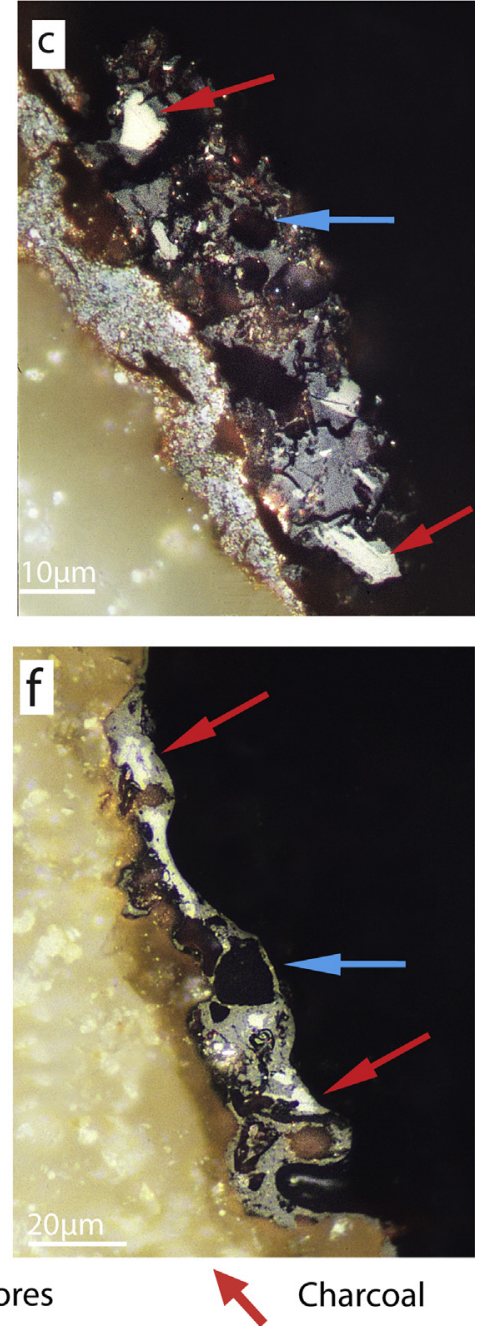

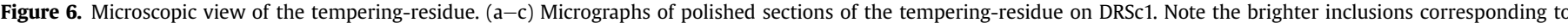

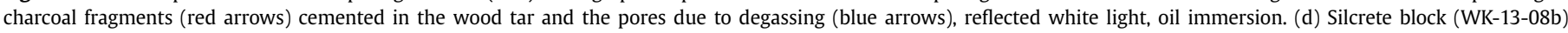

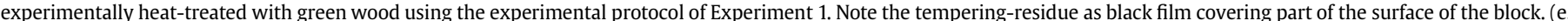

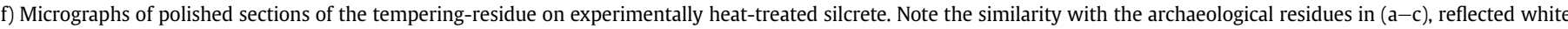
light, oil immersion (For interpretation of the references to colour in this figure legend, the reader is referred to the web version of this article.)

continuous flow of oxygen feeding the combustion. The temperature ramp and maximum temperatures endured by silcrete heat treated in this way must be expected to be a function of four factors:

[1] the species and moisture of the wood (A. erioloba produces significantly higher temperatures than all other tested taxa);

[2] the size of the pile of ember or the ash-cone and the fineness of the embers/ashes that allow or restrict oxygen flow to the centre of the pile;

[3] the speed of wind controlling the amount of oxygen available for the combustion (stronger wind produces higher temperatures and a less anoxic conditions within the embers);

[4] the size of the heated silcrete pieces (larger pieces of silcrete consume more energy of a given quantity of glowing embers, slowing down the heating process and preventing higher temperatures).

The temperature curves we measured during our experiments (Fig. 2) may not precisely reflect the heating conditions of MSA heat treatment. Temperatures in open fires may be unpredictable and difficult to reproduce. The total length of the treatment, i.e., the time the rock is held at maximum temperature for and the effective heating and cooling speeds must also be expected to be functions of the exact procedure used (amount of wood used, size of the piles of embers, the place of the silcrete within the fire). Fires may also be maintained for longer, and silcrete may have been left in the fire for longer than necessary. Our experiments should therefore be understood as an indication of a possibly used technique and they should highlight the tolerance of silcrete with regards to fast heating rates.

The maximum temperatures measured during our experiments using the Diepkloof plant species are similar to the heat treatment temperatures published by Brown et al. (2009) and Wadley and Prinsloo (2014), but our temperature ramps are significantly faster. Only one sample showed traces of overheating during our experiments, strongly supporting the model of heat-induced transformations in silcrete published by Schmidt et al. (2013). Higher maximum temperatures and even faster temperature ramps, as produced by A. erioloba wood, induced HINC-fractures in some of the samples but no clear relation between volume and overheating, as suggested by earlier works (Mercieca, 2000; 


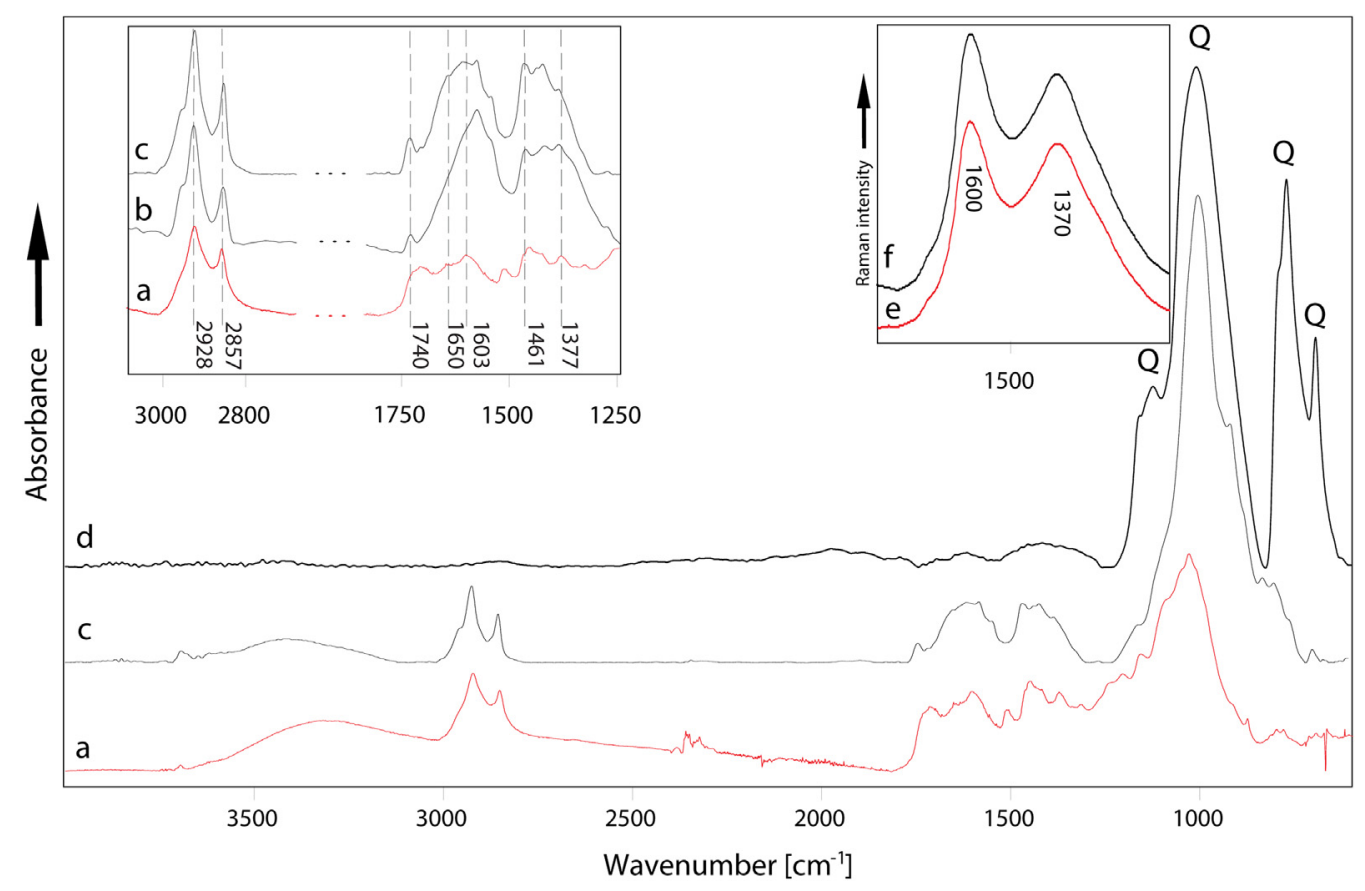

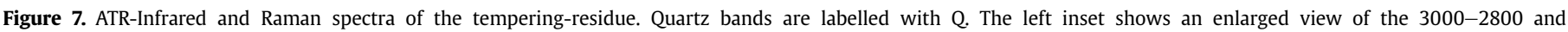

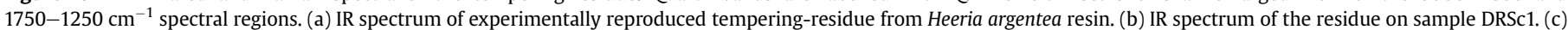

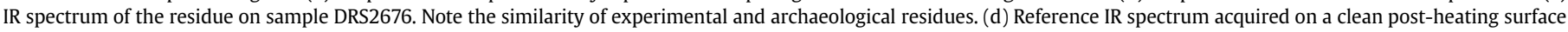

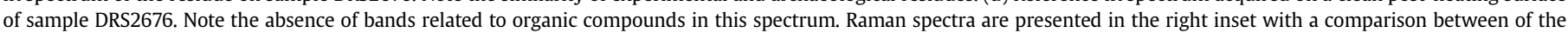
experimental tempering-residue (e) and the residue on sample DRS2676 (f). Spectra not smoothed but vertically offset for clarity.

Mercieca and Hiscock, 2008; Schmidt, 2014), was observed during our experiments. A possible explanation for this would be that impurities and inclusions in silcrete (such as iron oxide-hydroxides producing vapour pressure through $\mathrm{OH}$ loss) contribute to HINCfracturing alongside the known factors $\left(\mathrm{H}_{2} \mathrm{O}\right.$ formation from $\mathrm{SiOH}$, [Schmidt, 2014]). Further studies on where heat-induced failure occurs in silcrete will shed light on this hypothesis. One of the most interesting observations made during our analyses is the abundance of HINC-fractures on the archaeological material. This high frequency of HINC-fractures on the Diepkloof lithics suggests that MSA knappers accepted the risk of heat-induced failure as long as the resulting fragments remained knappable. The HINCfracturing may even have some advantages during the reduction of silcrete if breakages preferentially occur at discontinuities and flaws in the rock that would have caused fracture irregularities and problems during knapping. As the remaining pieces of silcrete resulting from heat-induced fracturing are well heat-treated and remain perfectly knappable, overheating during heat treatment may have been used as a sort of pre-selection for good-quality raw material.

Future experiments using different parts of domestic fires and different amounts of embers should address important questions like the reproducibility and variability of heat treatment in embers or in a fire.

\subsection{The formation of a tempering-residue}

We observed the formation of a black opaque temperingresidue during experimental heat treatment using the green wood of four plant species reported in the charcoal record of the Diepkloof HP layers (Cartwright, 2013). Of these four species, $H$. argentea, and S. laevigata belong to the family Anacardeaceae for which several studies have demonstrated the exudation of resins and gums (McNair, 1930; Joel and Fahn, 1980; Farrell et al., 1991).
There are reports of gum production of Diospyros (Nussinovitch, 2009) and resin production has been described for Podocarpus elongates (Charrié-Duhaut et al., 2013). When collecting the wood for this study, we observed resin exudations on the stems of the wood of the S. laevigata and $H$. argentea. Several studies have also reported gum and resin exudations for the genus Acacia (McNair, 1930; Lemenih et al., 2003; Pietarinen et al., 2004) and a black tempering-residue also resulted from some of our experiments with Acacia. We hypothesize that the tempering-residue found on experimental and archaeological silcrete formed by distillation during the combustion of the plant exudations. During this process, the distillation residue comes into contact with the silcrete surface that touches the hot embers from where the exudations originate, forming a black tempering-residue that tightly adheres to the silcrete surface. Anoxic or partly anoxic conditions within a pile of embers and an ash-cone at the base of a fire may be a prerequisite for the formation of such a tempering-residue because low levels of oxygen prevent the exudations from completely combusting (most of the available oxygen is used up in the zone of active combustion at the pile's surface). Our spectroscopic and microscopic analyses support this model of formation. The optical properties of the tempering-residue on archaeological and experimental samples and its structure, such as its specific low reflectance values, the degassing pores and the flow texture, indicate deposition as a hot fluid phase and are consistent with organic tar (Crelling et al., 2006). Natural wood tar is a product of the pyrolysis or carbonization of wood exudations (Bunbury, 1923) as they can be produced during burning of green wood containing sufficient moisture. Our infrared data also support this interpretation: all observed spectral features are consistent with organic tars produced by burning of green wood (Regert et al., 2003). Raman spectroscopic data are also consistent with this interpretation showing carbon-carbon bonds that are produced when organic matter is transformed through pyrolysis at high temperature 
(Tomasini et al., 2012). The presence of charcoal fragments (inertodetrinite [Taylor et al., 1998]) that are cemented within this organic tar indicates that the tempering-residue formed in the presence of ashes or embers. The differences observed in the infrared spectra of experimentally produced and archaeological tempering residues may be due to diagenesis. The region between $1750 \mathrm{~cm}^{-1}$ and $1250 \mathrm{~cm}^{-1}$ contains $\mathrm{C}-\mathrm{O}$ and $\mathrm{C}=\mathrm{O}$ absorption bands. The broad bands that appear in this region of archaeological residue spectra may result from diagenetically formed CO bonds. These diffuse underlying absorptions mask weak bands in this region and make it difficult to observe the sharp CO bands in the spectra. This is what one would expect from oxidation during burial and does not contradict the chemical similarity between experimental and archaeological residues.

Thus, our heat treatment experiments produced a surface residue structurally and chemically similar to the one observed on the Diepkloof artefacts. Our analyses also indicate that the mechanism of formation of this tempering-residue corresponds most likely to the pyrolysis of plant exudations that come into contact with the silcrete surface during heat treatment.

\subsection{Tempering-residue, hafting material or post-depositional processes?}

In light of our findings that the black residue consists of an organic tar formed by contact between silcrete and hot embers of a fire, it must be discussed whether such a residue may also form during post-depositional processes or unintentional discard in a fire. It must further be discussed whether a residue of a material used for hafting of stone tools, possibly chemically similar to a tempering-residue, may be mistaken for a tempering-residue. The strict association of tempering-residues with a specific family of surfaces on the artefacts appears to be the key element in clarifying these issues.

If the residue were produced through post-depositional processes or unintentional discard in a fire, we would expect that the entire outer surface of the artefacts exposed to the fire or the taphonomic agent would be covered by tar. In contrast to this, the wood tar observed on Diepkloof artefacts is only found on surfaces that already existed before heat treatment (i.e., removal scars predating heat treatment and naturally rolled/weathered surfaces). It is not observed on surfaces created by knapping after heat treatment. Furthermore, the archaeological tar is cross-cut by adjacent post-heating flake removal scars. This demonstrates that the Diepkloof tar formed prior to the final sequence of post-heattreatment-knapping, suggesting that it formed during the same stage of the chaîne opératoire as heat treatment itself. Thus, the observed Diepkloof tempering-residue cannot have formed by post-depositional processes after discard of the finished stone tools.

The Diepkloof wood tar is obviously not related to hafting because hafting materials would also not be cross-cut by flake scars since such materials are applied to the lithics after the tools are finished. Additionally, most hafting materials would cover both ventral and dorsal sides of an artefact (Charrié-Duhaut et al., 2013). Hafting materials that were reported from Diepkloof Rock Shelter also show different composition and structure than the observed tempering-residue. Although containing a substantial amount of plant resin, Diepkloof hafting materials contain fragmented bone and quartz grains and were not subjected to high temperatures (Charrié-Duhaut et al., 2013), in contrast to the tempering residue that consists of plant exudations transformed to tar at high temperatures and that contains only micrometre-sized fragments of charcoal.

\subsection{Similarities between experimental and archaeological heat treatment}

Although we cannot confirm that the procedure used during the MSA was identical to the one we tested during our experiments, both procedures must have been similar in two regards: [1] Direct heating in embers: the direct contact between a silcrete surface and hot embers of a fire seems to be a prerequisite for the formation of the observed archaeological tempering-residue. This makes the use of an indirect heating method like heat treatment in 'sand beneath a fire pit' (Brown et al., 2009) an unlikely scenario. [2] Fast heating rates: an additional argument for the similarity between archaeological and experimental procedures comes from the observation that both the experimental and archaeological silcrete artefacts exhibit similar heat-induced non-conchoidal fractures. During our experiments, HINC-fractures developed in some of the samples that endured heating rates of $8{ }^{\circ} \mathrm{C} /$ minute to $20{ }^{\circ} \mathrm{C} /$ minute. Indirect heating in a sand-bath produces significantly slower heating rates in the range of $0.4{ }^{\circ} \mathrm{C} /$ minute to $0.9{ }^{\circ} \mathrm{C} /$ minute (Eriksen, 1997) making HINC-fractures less likely (Mercieca, 2000; Mercieca and Hiscock, 2008; Schmidt, 2014; Wadley and Prinsloo, 2014). The presence of HINC-fractures on 7.2\% (Frans) and 10.5\% (Frank) of the analysed Diepkloof artefacts is therefore a supplementary argument for the use of a heat treatment procedure that involved heating rates similar to the ones in our experiments.

Based on the results of our experimental and archaeological study, we conclude that the Diepkloof HP artefacts were heattreated using a technique that involved rather fast heating and direct contact between the exposed silcrete surfaces and hot glowing embers of a fire. Even though indirect underground heating may theoretically also produce HINC-fracturing during the heating process, and one may argue that resin/gum containing plant material intermixed with sediment may theoretically produce wood tar during underground heating, we must await experimental and archaeological proof for the possible use of sandbath heating before drawing a definitive conclusion. However, until such proof will be brought forward, our heat-treatment-in-embers model appears to remain the best explanation of the archaeological data at Diepkloof.

\subsection{Comparison of our data with previously published data}

Using an experimental approach, Wadley and Prinsloo (2014) recently investigated the question of whether silcrete from South Africa could have been heat-treated using the glowing embers of a fire as predicted (Schmidt et al., 2013). In their study, they reached the conclusion that heat treatment in a bed of embers or using an open fire was not possible because three out of their six samples heated to $521-573{ }^{\circ} \mathrm{C}$ in a bed of embers and all three of their samples heated to $762{ }^{\circ} \mathrm{C}$ in a fire fractured. This article is not the place for a detailed comment on the work of Wadley and Prinsloo (2014) and we would only like to highlight that our analysis of the archaeological material from Diepkloof does not confirm their main hypothesis.

While we fully support their statement that heat treatment "requires skilled use of fire" (Wadley and Prinsloo, 2014: 49) and agree that heat treatment may be indicative of "complex cognition" (Op. cit.), our results suggest that the HP inhabitants of Diepkloof did heat-treat silcrete in hot glowing embers. Furthermore, the MSA knappers accepted the risk of heat-induced fracturing and continued to knap the remaining fragments when such fracturing occurred. Thus heat-induced fracturing during heat treatment cannot be interpreted as failure of the procedure but must be understood as recurrent part of the lithic reduction sequence. 


\subsection{Conclusion and implications for the South African MSA}

Heat treatment of silcrete marks a precocious and significant innovation within the South African Middle Stone Age that may reveal some of the key aspects of the techno-economic system of the MSA hunter-gatherers. While heat treatment alone is a significant technological innovation, it is crucial to fully understand its role and place within the lithic production sequence, the motivations for performing it, and the technical process used for it. Our study sheds light on the heat treatment procedure, raising important questions about the investment and complexity of the technical process (i.e., requiring more or less steps for its realization). It appears most likely that heat treatment of silcrete, as it was performed during the South African MSA, did not involve indirect heating in a sand-bath that would have demanded extra resources or investment in time as previously suggested (Brown et al., 2009; Brown and Marean, 2010; Wadley, 2013; Wadley and Prinsloo, 2014). In fact, the heat treatment procedure suggested by our data could have been conducted alongside other daily, fire-related activities, allowing for a highly efficient production of wellworkable raw materials for stone tool knapping, without interrupting or greatly slowing down the reduction sequence. Further studies of silcrete and the tempering residue will help to contextualize heat treatment within the South African MSA technoeconomic system and in the broader suite of innovations that appeared during this period. The complete chemical characterization of the heating-residue, using an appropriate set of analytical techniques, is also currently in progress and will be subject of another publication in the near future.

\section{Acknowledgements}

We thank the Deutsche Forschungsgemeinschaft (DFG) for funding of the research project 'Heat Treatment in the South African MSA' that made the present study possible (Grant Nr: CO 226/ 25-1, MI 1748/2-1, NI 299/25-1) and for funding the Agilent Cary 660 spectrometer used for parts of this study (MI 1748/1-1). We thank the French Ministry of Foreign affairs for funding the excavation at Diepkloof, Heritage Western Cape for authorizing these excavations and the South African Heritage Resources Agency for the permit for analysis. We also acknowledge the University of Cape Town for housing the DRS collections and logistic assistance during this study. Special thanks goes to Justin Pargeter for helping us with weighing of the samples and Jessica Plasket for her help during silcrete sampling in the West Coast. We also acknowledge Royden Wood and his staff for providing the facilities for experimental heat treatment.

\section{Appendix A. Supplementary data}

Supplementary data related to this article can be found at http:// dx.doi.org/10.1016/j.jhevol.2015.05.001

\section{References}

Backwell, L., d'Errico, F., Wadley, L., 2008. Middle Stone Age bone tools from the Howiesons Poort layers, Sibudu Cave, South Africa. J. Archaeol. Sci. 35, 1566-1580.

Brown, K., Marean, C., 2010. Wood fuel availability for heat treatment drives the rise and fall of silcrete as a raw material in the Middle Stone Age of South Africa, Asbstracts of the PaleoAnthropology Society 2010 Meetings. PaleoAnthropology A0001-A0040.

Brown, K.S., Marean, C.W., Herries, A.I.R., Jacobs, Z., Tribolo, C., Braun, D., Roberts, D.L., Meyer, M.C., Bernatchez, J., 2009. Fire as an engineering tool of early modern humans. Science 325, 859-862.

Bunbury, H.M., 1923. The Destructive Distillation of Wood. Benn Brothers, London.
Cartwright, C., 2013. Identifying the woody resources of Diepkloof Rock Shelter (South Africa) using scanning electron microscopy of the MSA wood charcoal assemblages. J. Archaeol. Sci. 40, 3463-3474.

Charrié-Duhaut, A., Porraz, G., Cartwright, C., De Araujo, M., Conan, J., Poggenpoel, C., Texier, P.-J., 2013. First molecular identification of a hafting adhesive in the Late Howiesons Poort at Diepkloof Rock Shelter, Western Cape, South Africa. J. Archaeol. Sci. 40, 3506-3518.

Clark, J.D., 1988. The Middle Stone Age of East Africa and the beginnings of regional identity. J. World Prehist. 2, 235-305.

Crabtree, D.E., Butler, B.R., 1964. Notes on experiment in flint knapping: 1 heat treatment of silica materials. Tebiwa 7,1-6.

Crelling, J., Glikson, M., Huggett, W., Borrego, A.G., Hower, J., Ligouis, B., Mastalerz, M., Misz, M., Suárez-Ruiz, I., Valentim, B., 2006. International Committee for Coal and Organic Petrology (ICCP), Atlas of anthropogenic particles. Geological Survey Open-File Study 06-01, Indiana.

Domanski, M., Webb, J.A., 1992. Effect of heat treatment on siliceous rocks used in prehistoric lithic technology. J. Archaeol. Sci. 19, 601-614.

Domanski, M., Webb, J.A., Boland, J., 1994. Mechanical properties of stone artefact materials and the effect of heat treatment. Archaeometry 36, 177-208.

Eriksen, B.V., 1997. Implications of thermal pre-treatment of chert in the German Mesolithic. In: Schild, R., Sulgostowska, Z. (Eds.), Man and Flint, Proceedings of the VII International Flint Symposium Warszawa-Ostrowiec Swietokrzyski, September 1995. Institute of Archaeology and Ethnology Polish Academy of Sciences, Warsaw, pp. 325-329.

Farrell, B.D., Dussourd, D.E., Mitter, C., 1991. Escalation of plant defense: do latex and resin canals spur plant diversification? Am. Nat. 138, 881-900.

Henshilwood, C.S., D'Errico, F., Marean, C.W., Milo, R.G., Yates, R., 2001. An early bone tool industry from the Middle Stone Age at Blombos Cave, South Africa: implications for the origins of modern human behaviour, symbolism and language. J. Hum. Evol. 41, 631-678.

Henshilwood, C.S., d'Errico, F., Yates, R., Jacobs, Z., Tribolo, C., Duller, G.A.T., Mercier, N., Sealy, J.C., Valladas, H., Watts, I., Wintle, A.G., 2002. Emergence of modern human behavior: Middle Stone Age engravings from South Africa. Science 295, 1278-1280.

Henshilwood, C.S., d'Errico, F., Watts, I., 2009. Engraved ochres from the Middle Stone Age levels at Blombos Cave, South Africa. J. Hum. Evol. 57, $27-47$.

Inizan, M.L., Roche, H., Tixier, J., 1976. Avantages d'un traitement thermique pour la taille des roches siliceuses. Quaternaria Roma 19, 1-18.

Joel, D.M., Fahn, A., 1980. Ultrastructure of the resin ducts of Mangifera indica L. (Anacardiaceae). 1. Differentiation and senescence of the shoot ducts. Ann. Bot. 46, 225-233.

Lemenih, M., Abebe, T., Olsson, M., 2003. Gum and resin resources from some Acacia, Boswellia and Commiphora species and their economic contributions in Liban, south-east Ethiopia. J. Arid Environ. 55, 465-482.

McBrearty, S., Brooks, A.S., 2000. The revolution that wasn't: a new interpretation of the origin of modern human behavior. J. Hum. Evol. 39, 453-563.

McNair, J.B., 1930. Gum, tannin, and resin in relation to specificity, environment, and function. Am. J. Bot. 17, 187-196.

Mercieca, A., 2000. An experimental study of heat fracturing in silcrete. Aust. Archaeol. 51, 40-47.

Mercieca, A., Hiscock, P., 2008. Experimental insights into alternative strategies of lithic heat treatment. J. Archaeol. Sci. 35, 2634-2639.

Micheelsen, H., 1966. The structure of dark flint from Stevns, Denmark. Medd. Dansk. Geol. Foren. 16, 285-368.

Mourre, V., Villa, P., Henshilwood, C.S., 2010. Early use of pressure flaking on lithic artifacts at Blombos Cave, South Africa. Science 330, 659-662.

Nussinovitch, A., 2009. Plant Gum Exudates of the World: Sources, Distribution, Properties, and Applications. CRC Press/Taylor \& Francis, Boca Raton.

Olausson, D.S., Larsson, L., 1982. Testing for the presence of thermal pretreatment of flint in the Mesolithic and Neolithic of Sweden. J. Archaeol. Sci. 9, 275-285.

Parkington, J., Rigaud, J.-P., Poggenpoel, C., Porraz, G., Texier, P.-J., 2013. Introduction to the project and excavation of Diepkloof Rock Shelter (Western Cape, South Africa): a view on the Middle Stone Age. J. Archaeol. Sci. 40, 3369-3375.

Pietarinen, S., Willfor, S., Holmbom, B., 2004. Wood Resin 8 in Acacia mangium and Acacia crassicarpa Wood and Knots. Appita Journal: Journal of the Technical Association of the Australian and New Zealand Pulp and Paper Industry 57, 146.

Porraz, G., Texier, P.-J., Archer, W., Piboule, M., Rigaud, J.-P., Tribolo, C., 2013. Technological successions in the Middle Stone Age sequence of Diepkloof Rock Shelter, Western Cape, South Africa. J. Archaeol. Sci. 40, 3376-3400.

Purdy, B.A., Brooks, H.K., 1971. Thermal alteration of silica minerals: an archeological approach. Science 173, 322-325.

Regert, M., Garnier, N., Decavallas, O., Cren-Olivé, C., Rolando, C., 2003. Structural characterization of lipid constituents from natural substances preserved in archaeological environments. Meas. Sci. Technol. 14, 1620-1630.

Schindler, D.L., Hatch, J.W., Hay, C.A., Bradt, R.C., 1982. Aboriginal thermal alteration of a Central Pennsylvania Jasper: analytical and behavioral implications. Am. Antiq. 47, 526-544.

Schmidt, P., 2013. Le Traitement Thermique des Matières Premières Lithiques : Que se Passe-t-il Lors de la Chauffe ? BAR International Series 2470 Archaeopress, Oxford.

Schmidt, P., 2014. What causes failure (overheating) during lithic heat treatment? Archaeol. Anthropol. Sci. 6, 107-112.

Schmidt, P., Masse, S., Laurent, G., Slodczyk, A., Le Bourhis, E., Perrenoud, C., Livage, J., Fröhlich, F., 2012. Crystallographic and structural transformations of 
sedimentary chalcedony in flint upon heat treatment. J. Archaeol. Sci. 39, 135-144.

Schmidt, P., Porraz, G., Slodczyk, A., Bellot-gurlet, L., Archer, W., Miller, C.E., 2013. Heat treatment in the South African Middle Stone Age: temperature induced transformations of silcrete and their technological implications. J. Archaeol. Sci. $40,3519-3531$.

Taylor, G.H., Teichmüller, D.A., Diessel, C.F.K., Littke, R., Robert, P., 1998. Organic Petrology. Gerbrüder Borntraeger, Berlin.

Texier, P.-J., Porraz, G., Parkington, J., Rigaud, J.-P., Poggenpoel, C., Tribolo, C., 2013. The context, form and significance of the MSA engraved ostrich eggshell collection from Diepkloof Rock Shelter, Western Cape, South Africa. J. Archaeol. Sci. $40,3412-3431$.
Tixier, J., Inizan, M.-L., Roche, H., Dauvois, M., 1980. Préhistoire de la pierre taillée. Terminologie et technologie. Cercle de Recherches et d'Etudes Préhistoriques, Antibes.

Tomasini, E.P., Halac, E.B., Reinoso, M., Di Liscia, E.J., Maier, M.S., 2012. Micro-Raman spectroscopy of carbon-based black pigments. J. Raman Spectrosc. 43, $1671-1675$.

Wadley, L., 2010. Compound-adhesive manufacture as a behavioral proxy for complex cognition in the Middle Stone Age. Curr. Anthropol. 51, 111-119.

Wadley, L., 2013. Recognizing complex cognition through innovative technology in Stone Age and Palaeolithic Sites. Cambridge Archaeol. J. 23, 163-183.

Wadley, L., Prinsloo, L.C., 2014. Experimental heat treatment of silcrete implies analogical reasoning in the Middle Stone Age. J. Hum. Evol. 70, 49-60. 